\title{
Comparison of CPG's for the diagnosis, prognosis and management of non-specific neck pain: a systematic review
}

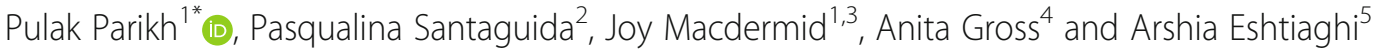

\begin{abstract}
Background: Neck pain (NP) is a very common musculoskeletal condition with potential for a high burden in disability and length of disorder. Clinical practice guidelines (CPG) give recommendations to clinicians for providing optimal care for patients however best practice recommendations are often contradictory. The purpose for this review was to conduct a SR of CPGs to assess the management recommendations for NP (diagnosis, treatment, prognosis, imaging).

Methods: Standard SR methodology was employed including a grey literature search (including the National Guideline Clearing House). Medline, Cinahl, Embase, ILC, Cochrane, Central, and Lilacs were searched from 1995-to March 2018. Two raters evaluated all citations and a third rater resolved any disagreements. The AGREE II was used to assess risk of bias of each CPG. Data was extracted and included CPG purpose, type of NP problem and clinical recommendations. The AGREE II critical appraisal tool was used to assess risk of bias of each CPG.

Results: From 640 articles, 241 were available for screening. A total of 46 guidelines were selected. CPG's were categorized by the NP population (General NP, whiplash, interventional, headache and risk for vertebral insufficiency) and type of clinical aim (diagnosis, prognosis, treatment, imaging). Each clinical NP population had a large overlap of clinical aims presented. The CPGs were directed to a variety of clinicians that included physicians, physiotherapists and chiropractors. Results suggest heterogeneity in CPG recommendations within each clinical aim. CPG characteristics accounting for these differences are outlined.

Conclusion: The majority of CPGs were developed for general NP that focused on treatment recommendations, with fewer number aimed at recommendations for diagnosis, prognosis, and outcomes. Heterogeneity of recommendations within the categories were noted as were potential factors associated with these differences, including CPG quality as assessed by the AGREE II.
\end{abstract}

Keywords: Clinical practice guidelines, Neck pain populations, Systematic review

\section{Background}

Neck pain (NP) is the most common musculoskeletal pathology second only to low back pain [1]. It is the fourth largest contributor to global disability with its prevalence ranging between 30 to $71 \%$ of the general population [2, 3]. Two thirds of adults are affected by NP at some time in their lives [4]. Not only does it have a potential for a high burden in disability most people with NP do not

\footnotetext{
* Correspondence: parikhp@mcmaster.ca; pulakpar@yahoo.com

${ }^{1}$ School of Rehabilitation Science, McMaster University, Hamilton, ON L8S

1C7, Canada

Full list of author information is available at the end of the article
}

experience a complete resolution of symptoms $[3,5]$. The economic burdens include cost of healthcare, reduced work productivity, work absenteeism and insurance that is estimated at 33.6 million annually $[2,5]$.

In efforts to decrease the amount of practice variation for NP, many guidelines have been developed to improve efficiency and effectiveness. Clinical practice guidelines (CPGs) are defined by the Institute of Medicine as "recommendations that intend to optimize patient care that are informed by systematic review (SR) of the evidence with an assessment of harms and benefits of alternative care options" [6]. They are intended to give best practice

(c) The Author(s). 2019 Open Access This article is distributed under the terms of the Creative Commons Attribution 4.0 International License (http://creativecommons.org/licenses/by/4.0/), which permits unrestricted use, distribution, and reproduction in any medium, provided you give appropriate credit to the original author(s) and the source, provide a link to the Creative Commons license, and indicate if changes were made. The Creative Commons Public Domain Dedication waiver (http://creativecommons.org/publicdomain/zero/1.0/) applies to the data made available in this article, unless otherwise stated. 
guidance and recommendations to clinicians for providing optimal care for patients. However, there has been mounting criticism that recommendations across different CPGs are often contradictory. Due to a large number of guidelines available for NP, clinicians often find it challenging to determine which guidelines are credible and of high quality. Many of the commonly used guidelines for NP have been questioned for their methodological quality, validity and reliability [7-9]. Furthermore, evidence for the treatment of mechanical NP is often of low quality and conflicted $[10,11]$, possibly resulting in a difference between the recommendations. Despite this, patients that receive adherent care in relation to CPG's for NP have had significantly lower visits to health care providers, decreased use of prescription medication and fewer diagnostic images [12, 13]. As such, the pursuit of guideline development, if originating from a strong scientific and pragmatic foundation is highly promising to the successful identification and treatment of neck pain.

To date, no previous research has systematically summarized and appraised all relevant CPG's for the management of NP. The purpose of this SR was not only to summarize the existing evidence regarding all CPGs regarding NP but also to provide a "panoramic view" of the CPG literature with an appraisal of the methodological quality. In the context of NP, an SR is ideal to provide the evaluation of the evidence from many different clinical settings, professions that treat NP and different countries where guidelines are developed. NP's widespread frequency and reoccurrence can cause differentiating levels of pain and disability, highlighting the need for a global summary of findings.

\section{Methods}

\section{Search strategy}

This SR was an update of an existing review that was updated for CPG's only [14]. A search strategy was developed with consultation from a health sciences librarian that included reviews from 2000 to 2012. An update was systematically undertaken from January 2012 to March 2018 for CPGs only. Details of the search strategy are outlined in detail here [14]. The following databases were searched: Medline, PubMed, Embase, Cochrane Database, CINAHL, ILC, LILACS and CENTRAL along with the grey literature. The grey literature included but was not limited to the National Guideline Clearinghouse, Canadian Medical Association, National Institute of Health and Clinical Excellence (NICE) Guidance, NICE pathways, World Health Organization and the American College of Physicians Clinical Recommendations. Search terms used within the databases for all areas in the overview of reviews across different clinical areas for the management of NP can be found here (Additional file 1: Appendix A).

\section{Selection of CPGs}

CPG's focusing on any form of management of neck pain were eligible. CPGs are defined as systematically developed statements to assist practitioners and patient decisions for specific clinical circumstance; they can be developed by local, regional, national or international groups or affiliated governmental organizations [14]. Consensus statements are similar but reflect a different methodology for deriving recommendations. Clinical algorithms are also variable in how they present recommendations and are often included within CPG's. Therefore, consensus statements and algorithms were only included if they were a part of a CPG. Articles had to include populations that had any type of NP.

Citations identified within the search were uploaded into a SR software (DistillerSR) and screening using a standardized form for eligibility. SR and CPGs were eligible but narrative reviews, commentaries, editorials were excluded. Two independent raters screened the articles at titles and abstract and full text with conflicts resolved between the screeners. If the screeners were unable to resolve conflicts, a senior investigator made the final decision for eligibility.

The following criteria were used to include CPGs: 1) All CPGs that included recommendations 2) English language; 3) Diagnosis of non-malignant NP that included adult (>18 years of age) populations; 4) NP defined as pain from the occiput to upper thoracic spine ( $\mathrm{T} 1$ to $\mathrm{T} 6$, mid upper back) and can include upper regions of the torso or shoulder area; 5) General musculoskeletal or chronic pain guidelines that could potentially include NP populations; Articles were excluded if they met the following criteria: 1) narrative reviews or articles that only contain consensus statements or algorithms; 2 ) included children (<18 years of age); 3 ) trauma associated with fracture or head injury; 4) definite or possible long tract neurological signs (i.e. myelopathies); 5) NP caused by other pathological entities (i.e. tumor, infections); 6) headache not of cervical origin but associated with the neck (i.e. migraine headache).

\section{Critical appraisal of guidelines}

Appraisal of the eligible guidelines was conducted using the Appraisal of Guidelines for Research and Evaluation version II (AGREE II). It is the most commonly used guideline appraisal tool [15] that includes 23 criteria (items) organized over 6 domains and two overall assessments. The items within the first 23 categories are rated on a 7-point scale (strongly agree to strongly disagree). The overall guideline quality is rated on a 7-point scale (lowest possible quality to highest possible quality). A 
second overall assessment consists of a recommendation provided on whether to use the guideline in practice or not (recommendation for use: yes, yes with modifications, no). Both overall assessment criteria should consider the 23 items evaluated beforehand and the resulting domain scores but should not be calculated from them.

Two to four independent researchers appraised all included guidelines. Each investigator was trained using the web tutorials provided on the AGREEPLUS website in addition to individual one on one sessions with a senior researcher. Discussions were held between the investigators with regards to overall guideline quality. Final grading was determined using the AGREE II scoring system for each domain as a \%. The overall guideline quality scores were based out of 7 with recommendations for use in practice had three options (yes, yes with modifications or no).

\section{Data extraction}

One researcher extracted guideline data and a second checked the data. Extracted elements were organized in tabular format and included demographic information (country of origin, professional composition panel), aim of CPG recommendations (diagnosis, prognosis, treatment, imaging) and specific recommendations grouped according to the CPG intent of diagnosis, prognosis, interventions and imaging.

Recommendations from each of the guidelines were organized via tables to facilitate comparison between them based upon their intention. They were divided into those that 1) recommended specific course of action 2) recommended against a specific course of action 3) did not note any course of action (for example, no recommendation for duration of treatment) 4) explicitly noted that there was no evidence to support of refute the recommendation.

\section{Results}

Our search yielded 3082 citations from our databases and 20 from other grey literature sources for a total of 3102 (Additional file 2: Appendix B). We removed 224 titles and abstracts that were duplicates. A total of 2880 citations were screened at title and abstract. Of those, 2239 (76\%) did not meet the eligibility criteria. This left 641 articles for which full text was obtained for further screening. Of those, 244 CPGs were included. Two independent reviewers further screened the 244 CPGs that remained. We found 46 (1.5\%) guidelines that were deemed admissible and included for appraisal and review.

The majority of guidelines originated from Australia, Canada, United States and the UK (93\%) (Additional file 3: Appendix C). CPG authors and committee members included physicians, physiotherapists, chiropractors, nurses, osteopaths, massage therapists and academics. Medical doctors authored the majority of interventional guidelines $(N=8)$ and in contrast physiotherapists and chiropractors were the primary leads in CPG's for the whiplash, NP and headache guidelines $(N=28)$.

\section{Guideline quality}

The overall quality of the included guidelines varied greatly (Additional file 4: Appendix D). When comparing all the guidelines there was a linear progression in the average of the total scores over the years (Fig. 1). Newer guidelines scored higher overall $\left(\mathrm{r}^{2}=.53\right)$. Guidelines scored poorly in domain- 5 (applicability), domain- 6 (editorial independence) and domain-3 (rigor of development). With the exception of five, guidelines did not adequately describe facilitators and barriers to their application, give recommendations on how to be put into practice and outline the potential resource implications of applying the recommendations given [16-20]. Guidelines also lacked a description of the funding bodies and their influence on the content of the guideline and competing interests development group [21-42]. Over half of the guidelines had major limitations with systematic search methods used for evidence, criteria of selecting evidence and adequate descriptions of the strengths and limitations of the body of evidence [21, 22, $25,26,29,31,32,34-37,39,42-50]$. The methods for formulating the recommendations in these guidelines were often not described along with a (lack of) link given to the supporting evidence. Domains-1,2 and 4 scored better for all the guidelines throughout the diagnoses.

\section{General neck pain guidelines}

A total of 20 guidelines that had a specific diagnosis of NP and associated disorders were grouped (Table 1). Publication dates spanned from 2003 to 2018. These included three guidelines that referenced cervical radiculopathy $[45,51]$. All guidelines were authored by either physician, physiotherapist or chiropractor groups with the exception of one [38]. The majority of the guidelines $(17 / 20)$ failed to identify barriers and facilitators to implementation, strategies to improve uptake and outline resource implication of applying the guideline $[21,22$, $33,36-45,51-53]$. . Half of the guidelines (10/20) showed minimal evidence of editorial independence as the majority of guidelines in this group were funded by groups associated with their authors [21, 22, 33, 36-42]. The AGREE scores improved for guidelines published from 2012 onwards (Fig. 1). Five guidelines in this group were deemed to have a high overall AGREE II score [16, $45,51,52,54]$. 


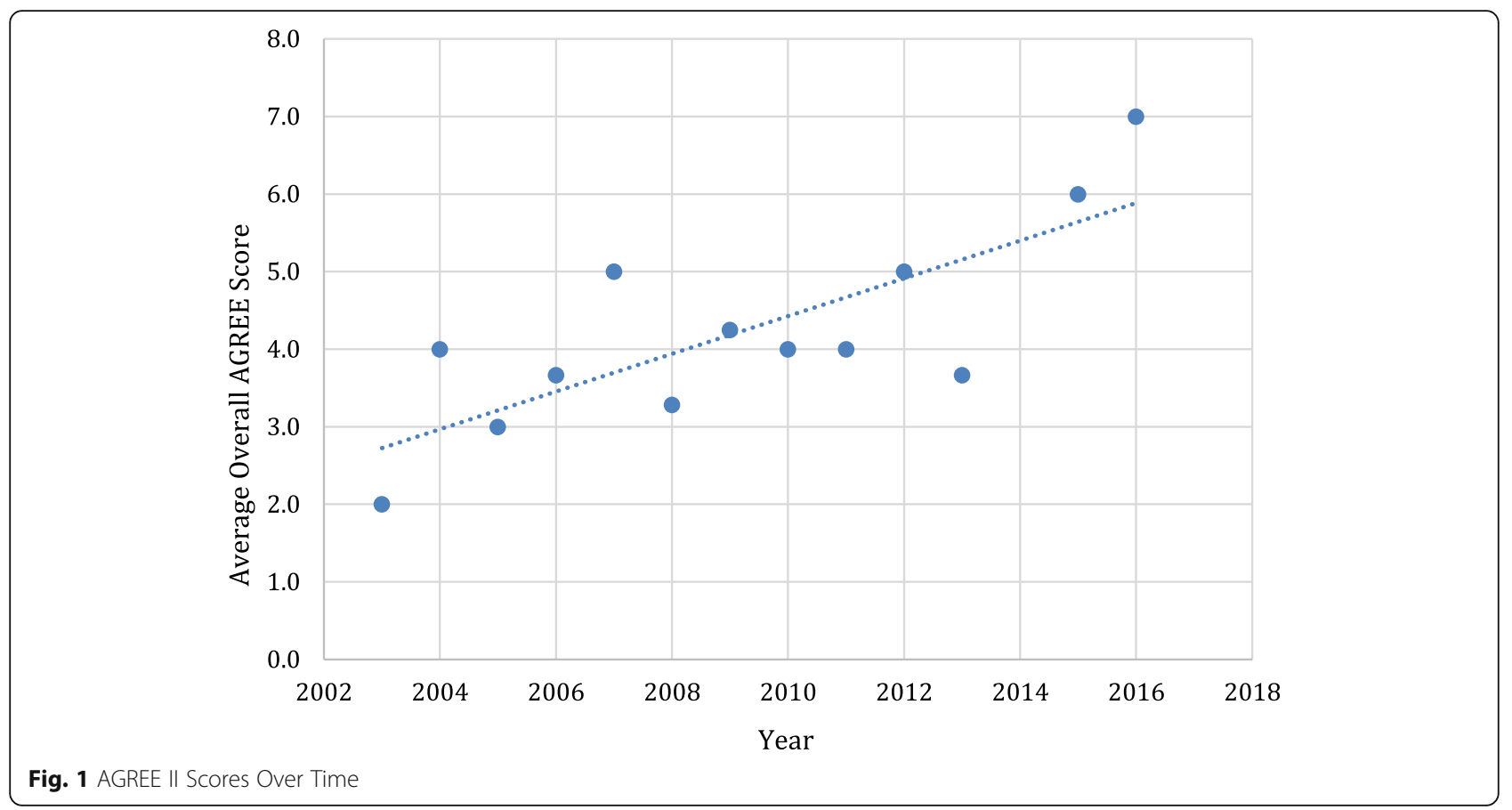

Table 1 AGREE II scores General Neck Pain Guidelines

\begin{tabular}{|c|c|c|c|c|c|c|c|c|}
\hline Author & Year & $\begin{array}{l}\text { Scope and } \\
\text { Purpose }\end{array}$ & $\begin{array}{l}\text { Stakeholder } \\
\text { involvement }\end{array}$ & Rigor of Development & $\begin{array}{l}\text { Clarity of } \\
\text { Presentation }\end{array}$ & Applicability & $\begin{array}{l}\text { Editorial } \\
\text { Independence }\end{array}$ & $\begin{array}{l}\text { Overall } \\
\text { Score }\end{array}$ \\
\hline French [21] & 2003 & 53.7 & 53.7 & 16.7 & 44.4 & 22.2 & 2.8 & 2 \\
\hline ANAES [22] & 2003 & 50.0 & 52.8 & 19.8 & 36.1 & 22.9 & 8.3 & 2 \\
\hline Anderson-Peacock [33] & 2005 & 79.6 & 63.0 & 58.3 & 79.6 & 40.3 & 47.2 & 5 \\
\hline Bussieres [43] & 2008 & 72.2 & 73.6 & 40.6 & 61.1 & 32.3 & 72.9 & 4 \\
\hline Guzman [52] & 2008 & 72.2 & 83.3 & 67.7 & 77.8 & 39.6 & 91.7 & 6 \\
\hline PAC [36] & 2009 & 19.4 & 22.2 & 15.6 & 83.3 & 20.8 & 12.5 & 1 \\
\hline AAMPG [53] & 2010 & 64.8 & 75.9 & 53.5 & 81.5 & 31.9 & 58.3 & 5 \\
\hline New York State Workers [37] & 2010 & 58.3 & 25.0 & 23.7 & 63.9 & 4.2 & 4.2 & 2 \\
\hline Bono [44] & 2010 & 77.8 & 52.8 & 40.6 & 58.3 & 29.2 & 79.2 & 4 \\
\hline Brosseau [38] & 2012 & 61.1 & 59.3 & 55.6 & 48.1 & 2.8 & 19.4 & 4 \\
\hline Monticone [39] & 2013 & 50.0 & 38.9 & 44.8 & 58.3 & 16.7 & 8.3 & 3 \\
\hline SIGN [16] & 2013 & 66.7 & 77.8 & 74.0 & 77.8 & 68.8 & 54.2 & 6 \\
\hline Newman [40] & 2013 & 61.1 & 50.0 & 58.3 & 75.0 & 35.4 & 16.7 & 5 \\
\hline Bryans [41] & 2014 & 69.4 & 33.3 & 50.0 & 66.7 & 20.8 & 37.5 & 3 \\
\hline Colorado Division [42] & 2014 & 61.1 & 41.7 & 19.8 & 83.3 & 35.4 & 8.3 & 3 \\
\hline Bussieres [17] & 2016 & 88.9 & 55.6 & 66.7 & 72.2 & 62.5 & 79.2 & 5 \\
\hline Cote [54] & 2016 & 83.3 & 86.1 & 75.0 & 80.6 & 52.1 & 91.7 & 7 \\
\hline Blanpied [45] & 2017 & 77.8 & 52.8 & 40.6 & 58.3 & 29.2 & 79.2 & 6 \\
\hline Kjaer [51] & 2017 & 97.2 & 86.1 & 72.9 & 83.3 & 18.8 & 87.5 & 7 \\
\hline Bier [56] & 2018 & 72.2 & 55.6 & 41.7 & 77.8 & 25.0 & 66.7 & 4 \\
\hline
\end{tabular}




\section{Diagnosis}

Many CPG's defined NP differently (Additional file 5: Appendix E). This included their definition for the classification of the duration of NP (acute, sub-acute and chronic) and the severity given for the diagnosis. The majority of guidelines published prior to 2010 did not differentiate on duration of NP [37, 52, 53, 55]. Three guidelines used the Bone and Joint classification (Grade $0-4)$ for diagnosis comparison [17, 52, 54]. Many of the guidelines did not differentiate on severity or classify NP at all $[16,38,41,51,53,55,56]$. When guidelines outlined durations for NP, often they conflicted on their time frames. Guidelines outline acute pain as $0-1$ month $[38,39,41]$ but also as $0-3$ months $[17,53,54,57]$. Of the guidelines that outlined duration of NP, all the guidelines agreed that chronic pain was that which was greater than 3 months [16, 17, 38, 39, 41, 45, 53, 54, 57].

\section{Prognosis}

All guidelines indicative of prognostic factors for general NP outlined neurological symptoms as a factor associated with poor prognosis $[37,39,42,43,52-54,57]$ with the exception of the two most recent published guidelines [45, 56] (Additional file 6: Appendix F). Other common factors included age [39, 42, 43, 52-54, 57], psychological factors [39, 42, 43, 45, 52-54, 56, 57], and pre-existing NP [39, 42, 43, 45, 52, 54, 56, 57]. Aside from these, a great deal of heterogeneity existed between the guidelines. Only three of the eighteen guidelines identified pain intensity and disability as poor prognostic indicators for general NP [39, 43, 45].

Various factors were described for psychological influences upon NP prognosis (Additional file 7: Appendix G). Passive coping [39, 42, 43, 52, 54, 56] (defined by strategies that relinquish control of pain to others or to allow other life areas to be affected by pain [58]) and depressive symptoms [37, 39, 42, 43, 54] were the most commonly reported. Other common factors included post-traumatic stress $[37,43,45,54]$, kinesophobia $[39,43,52,54]$ and anxiety $[37,39,52,54,56]$.

\section{Intervention}

Of all guidelines reporting interventions for NP [16, 17, $37-39,41,42,51-57,59]$, all but one did not include active exercise as a beneficial treatment [38]. All but two guidelines recommended manipulation and mobilization as an intervention for NP $[38,53]$. The majority of guidelines recommend a use of a combination of exercise, manual therapy and modalities (multi-modal care) $[16,17,39,41,42,45,51,53,54,56,57]$. as well as education (such as no rest greater than 3 days and staying active) however four guidelines stated that education was not beneficial $[17,53,54,57]$. There was quality of inconsistent evidence for commonly used treatments such as electrotherapy, traction, laser therapy, acupuncture and heat/cold (Additional file 8: Appendix H). Of all the guidelines for general NP, half recommended the use of medication alone or in combination with other treatments [16, 17, 37, 39, 42, 51, 54, 55] (the majority authored by physicians). Common medications reported were Non-Opioid Analgesics such as NSAIDS (both oral and topical), Paracetamol and Opioids. The majority of guidelines were against the use of soft collars [17, 37, 39, $42,52-55,57]$. Pulsed electro-magnetic therapy was recommended by five guidelines as a beneficial treatment $[16,39,52,53]$. Many interventional recommendations did not change over time as there was consistency for exercise and mobilization and manipulation but a large heterogeneity among all other treatments.

\section{Diagnostic imaging}

Seven guidelines for general NP recommended using the Canadian Cervical Spine Rule in their use of X-ray [43, $45,52-54,57,60]$ within the acute phase (Additional file 9: Appendix I). Six CPGs did not recommend the use of a routine $\mathrm{x}$-ray for a diagnosis of acute or subacute NP [40, 43, 45, 52-54, 57] however chronic NP was considered differently and the recommendations for $\mathrm{x}$-ray were identified in five CPGs $[37,40,53,55,60]$. Magnetic Resonance Imaging (MRI) was considered the best imaging technique for NP [39, 40, 43, 53, 55, 60]. For radicular symptoms both the use of MRI or Computed Tomography (CT) scan were presented as options [37, 39, 40, 45, 52, 53, 55, 60]. Electromyogram (EMG) studies were not recommended because of low diagnostic. CPG's provided conflicting recommendations for studies such as myelography, bone scan, diagnostic injections and tomography.

\section{Whiplash}

Seven guidelines that exclusively pertained to whiplash were identified (Table 2) [23-25, 61-64]. Publication dates spanned from 2005 to 2014. Whiplash was classified using the Quebec Task Force for all guidelines [65]. Overall scores in this group did not follow the general trend in that their methodological quality did not improve with more current publication dates. All guidelines were authored by either physiotherapist or chiropractor lead groups. Every guideline in this group did not adequately identify barriers and facilitators to implementation, strategies to improve uptake and resource implications of applying the guideline with the exception of one [18]. The majority of the guidelines (5/7) did not demonstrate editorial independence with a lack of neutrality from the funding bodies [23-26, 63]. Many guidelines (3/7) did not outline the process used to gather and synthesize the evidence, the methods used to formulate the recommendations and to update them $[25,26$, 
Table 2 AGREE II scores Whiplash Guidelines

\begin{tabular}{|c|c|c|c|c|c|c|c|c|}
\hline Author & Year & $\begin{array}{l}\text { Scope and } \\
\text { Purpose }\end{array}$ & $\begin{array}{l}\text { Stakeholder } \\
\text { involvement }\end{array}$ & $\begin{array}{l}\text { Rigor of } \\
\text { Development }\end{array}$ & $\begin{array}{l}\text { Clarity of } \\
\text { Presentation }\end{array}$ & Applicability & $\begin{array}{l}\text { Editorial } \\
\text { Independence }\end{array}$ & $\begin{array}{l}\text { Overall } \\
\text { Score } \\
\end{array}$ \\
\hline Leigh [46] & 2005 & 55.6 & 36.1 & 37.5 & 36.1 & 18.8 & 58.3 & 3 \\
\hline Mercer [24] & 2007 & 80.6 & 75.0 & 62.5 & 44.4 & 25.0 & 8.3 & 5 \\
\hline TRACsa [23] & 2008 & 75.0 & 72.2 & 61.5 & 80.6 & 37.5 & 8.3 & 6 \\
\hline Davis [25] & 2009 & 55.6 & 30.6 & 20.8 & 41.7 & 14.6 & 8.3 & 2 \\
\hline Bryans [26] & 2010 & 75.0 & 55.6 & 33.3 & 47.2 & 35.4 & 12.5 & 3 \\
\hline Moore [18] & 2010 & 94.4 & 77.8 & 92.7 & 80.6 & 85.4 & 70.8 & 7 \\
\hline MAA [63] & 2014 & 86.1 & 69.4 & 54.2 & 88.9 & 22.9 & 20.8 & 4 \\
\hline
\end{tabular}

46]. Two guidelines were deemed to have high overall AGREE II score [18, 23].

\section{Diagnosis}

The definition for the duration of whiplash differentiated greatly among included guidelines. Half defined acute whiplash as 0 to 12 weeks [23, 25, 46, 63] (Additional file 5: Appendix E). Three guidelines defined acute whiplash from less than one to two weeks [24, 26, 64] with a subacute phase from 1 to 12 weeks. Chronic whiplash was defined as greater than 12 weeks by all but one guideline [61]. Every guideline used the Quebec Task Force for classification of whiplash (0 to 4 grades). Four of the eight guidelines recommended the Visual Analog Scale and Neck Disability Index as outcome measures for diagnosis and treatment $[23,25,46,63]$. A large amount of heterogeneity existed between the recommendations for clinical diagnostic tests and assessment procedures.

\section{Prognosis}

All included guidelines for whiplash indicated that the presence of some psychological factors provided evidence of poor prognosis (Additional file 6: Appendix F). All but one guideline [61] described high initial pain scores as a factor for poor prognosis. Other common factors related to poor prognosis were older age [26, $27,61,64]$, pre-existing NP [25, 26, 46, 64] and high levels of self-reported disability [23, 25, 46, 63]. The guidelines showed conflicted recommendations for other factors that included collision/trauma type, imaging testing and high amounts of health care usage. Other factors commonly reported were cold sensitivity $[23,63]$, lack of $\operatorname{ROM}[23,61,63]$ and gender (female) $[26,61,64]$.

Many factors were identified as psychological influences associated with poor prognosis following whiplash diagnosis (Additional file 7: Appendix G). The most common cause for poor prognosis was passive coping $[18,23,26,61,63]$. Other common factors included depression $[18,26,46,63]$, catastrophization [18, 23, 26, $63]$ and anxiety $[18,23,26,63]$.

\section{Intervention}

All guidelines agreed that active exercise was the most beneficial intervention for whiplash associated disorders regardless of the duration of symptoms [23, 25, 26, 46, 61, 63, 64]. Manipulation, mobilisation and education were also recommended throughout all grouped guidelines (Additional file 8: Appendix $\mathrm{H}$ ). There were conflicting recommendations for commonly used interventions such as electrotherapy, laser, ultrasound, medication, acupuncture, massage, pulsed electromagnetic therapy, biofeedback and heat/cold. Psychological interventions were recommended by the majority of guidelines $(6 / 7)[23,26$, $46,61,64]$. The use of soft collars [23, 24, 64] and surgery $[23,25,63]$ were not recommended.

\section{Imaging}

Five guidelines referred to imaging for whiplash [23, 25, 45, 63, 64] (Additional file 9: Appendix I). Three out of five of the guidelines referred to using the Canadian Cervical Spine rule to rule out serious pathology following acute whiplash injury [23, 45, 63]. Four guidelines recommended the use of MRI, CT or X-ray for those patients grouped only within a diagnosis category of grade 3 or higher $[25,45,63,64]$. Routine imaging was not recommended by all guidelines.

\section{Invasive techniques}

Ten guidelines were deemed eligible pertaining to interventional techniques (Table 3 ). These included invasive interventions such as facet joint injections, nerve blocks, neuro-augmentation (spinal cord stimulation and peripheral nerve stimulation), endoscopic discectomy and implantable drug delivery systems. Guideline publication dates spanned from 2005 to 2013. All but one guideline focused upon chronic neck pain [28]. However, no guideline provided definitions for chronic neck pain (type or chronicity). All the guidelines were authored by physician groups. Three lead authors authored all the included interventional pain guidelines (Easa [28]; Boswell [47, 48]; Manchikanti [19, 49, 50, 66-69]). All failed to outline barriers and facilitators to implementation, strategies to improve uptake and resource implications of 
Table 3 AGREE II Scores for Invasive Technique Guidelines

\begin{tabular}{|c|c|c|c|c|c|c|c|c|}
\hline Author & Year & $\begin{array}{l}\text { Scope and } \\
\text { Purpose }\end{array}$ & $\begin{array}{l}\text { Stakeholder } \\
\text { involvement }\end{array}$ & $\begin{array}{l}\text { Rigor of } \\
\text { Development }\end{array}$ & $\begin{array}{l}\text { Clarity of } \\
\text { Presentation }\end{array}$ & Applicability & $\begin{array}{l}\text { Editorial } \\
\text { Independence }\end{array}$ & $\begin{array}{l}\text { Overall } \\
\text { Score }\end{array}$ \\
\hline Boswell [47] & 2005 & 65.3 & 58.3 & 42.2 & 51.4 & 26.0 & 56.3 & 4 \\
\hline Boswell [48] & 2007 & 72.2 & 77.8 & 30.6 & 33.3 & 40.3 & 55.6 & 4 \\
\hline $\begin{array}{l}\text { Manchikanti, \{Reassessment of Evidence } \\
\text { Synthesis\} [67] }\end{array}$ & 2008 & 68.5 & 33.3 & 60.4 & 57.4 & 18.1 & 61.1 & 4 \\
\hline Manchikanti, \{Evidence-Based Guidelines\} [68] & 2009 & 77.8 & 59.7 & 35.9 & 63.9 & 37.5 & 72.9 & 5 \\
\hline $\begin{array}{l}\text { Manchikanti, } \\
\text { \{Review of neurophysiologic basis\} [49] }\end{array}$ & 2009 & 47.2 & 30.6 & 36.5 & 65.3 & 15.6 & 58.3 & 3 \\
\hline $\begin{array}{l}\text { Manchikanti, \{Review of therapeutic } \\
\text { interventions\} [66] }\end{array}$ & 2009 & 43.1 & 26.4 & 34.4 & 51.4 & 16.7 & 60.4 & 3 \\
\hline Manchikanti, \{An algorithmic approach\} [50] & 2009 & 53.7 & 35.2 & 30.6 & 77.8 & 40.3 & 55.6 & 4 \\
\hline $\begin{array}{l}\text { Manchikanti, \{An introduction to an } \\
\text { evidence-based approach\} [19] }\end{array}$ & 2009 & 88.9 & 44.4 & 52.1 & 52.8 & 54.2 & 87.5 & 5 \\
\hline Easa [28] & 2011 & 81.5 & 35.2 & 54.9 & 46.3 & 13.9 & 44.4 & 4 \\
\hline Manchikanti [69] & 2013 & 77.8 & 66.7 & 64.6 & 77.8 & 29.2 & 83.3 & 5 \\
\hline
\end{tabular}

applying the guideline with the exception of one [19]. Overall scores for the guidelines did not improved since 2004. The highest quality guidelines were those of Manchikanti, followed by Easa [28] and Boswell [47].

\section{Diagnosis}

All guidelines for invasive techniques recommended similar interventions for diagnosis [19, 28, 47, 49] and these included transforaminal epidural steroid injections, selective nerve root blocks and facet joint nerve blocks for those with chronic NP (Additional file 10: Appen$\operatorname{dix} J$ ).

\section{Prognosis}

All guidelines in this group did not formally cover prognostic indicators. Only one guideline recommended age $>50$ being a factor for a positive outcome with transforaminal epidural steroid injections [28].

\section{Intervention}

Therapeutically, all invasive technique guidelines recommended epidural steroid injections, medial branch blocks and percutaneous adhesiolysis for chronic NP. The use of Implantable intrathecal systems was originally supported [19, 47]. However, Manchikanti highlights the limited available evidence surrounding its efficacy in managing pain. Radiofrequency neurotomy used for chronic neck pain is recommended by all guidelines except Easa's [28] that did not cover this treatment modality. Boswell's guidelines [47] specifically recommend medial branch neurotomy but also deemed intraarticular facet joint injections to be ineffective (Machikanti similarly mentioned limited evidence supporting its use).

Notable differences existed between the recommendations of interventional-focused guidelines and general
NP guidelines that have an interventional section. While interventional pain guidelines strongly supported the use of percutaneous adhesiolysis, two other physician authored guidelines by the Colorado Division of Workers [42] and the New York Worker's Compensation Board [37] recommended against its use. These latter mentioned guidelines along with three others [23, 63] did not recommend steroid injections, despite strong consensus between interventional-focused guidelines on the treatment's efficacy.

The general NP guidelines, with agreement, recommended against the use of botulinum toxin injections, prolotherapy and disc decompression. Moreover, the guidelines generally advocated the use of surgery in a select or few situations, emphasizing its use only in complex and high-pain cases (Additional file 11: Appendix K).

\section{Imaging}

All the guidelines within this group did not provide an in-depth comparison of various neuroimaging tools such as MRI and CT. However, they did recommend against the use of provocation discography underlined by false-positive rates it tends to produce.

\section{Neck pain w/associated headache}

Four guidelines were included within the diagnosis of headache from 2011 to 2014 (Table 4) [20, 29, 30, 62]. Three out of four guidelines were completed by physician groups [20, 29,30]. The overall AGREE scores did not change over time. The majority of the guidelines ( $3 /$ 4) failed to outline barriers and facilitators to implementation, strategies to improve uptake and resource implications of applying the guidelines [29, 30, 41].. Two guidelines demonstrated editorial independence being 
Table 4 AGREE II Scores for Neck Pain w/Headache Guidelines

\begin{tabular}{|c|c|c|c|c|c|c|c|c|}
\hline Author & Year & $\begin{array}{l}\text { Scope and } \\
\text { Purpose }\end{array}$ & $\begin{array}{l}\text { Stakeholder } \\
\text { involvement }\end{array}$ & $\begin{array}{l}\text { Rigor of } \\
\text { Development }\end{array}$ & $\begin{array}{l}\text { Clarity of } \\
\text { Presentation }\end{array}$ & Applicability & $\begin{array}{l}\text { Editorial } \\
\text { Independence }\end{array}$ & $\begin{array}{l}\text { Overall } \\
\text { Score }\end{array}$ \\
\hline Sandrini [29] & 2011 & 50.0 & 41.7 & 43.8 & 75.0 & 10.4 & 16.7 & 4 \\
\hline Beithon [20] & 2013 & 88.9 & 75.0 & 64.6 & 75.0 & 68.8 & 95.8 & 6 \\
\hline Douglas [30] & 2014 & 47.2 & 52.8 & 50.0 & 61.1 & 20.8 & 4.2 & 4 \\
\hline Bryans [62] & 2014 & 61.1 & 61.1 & 65.5 & 66.7 & 31.3 & 66.7 & 5 \\
\hline
\end{tabular}

unbiased without competing interests [20, 41]. One guideline was deemed to have a high AGREE II score [20].

\section{Diagnosis}

Guidelines in this category did not routinely distinguish between primary and secondary headache. For the purpose of this paper we only extracted information for those headache types related to NP disorders and this included the focus of recommendations taken in regard to non-acute, non-traumatic and cervicogenic (secondary) headache. Sandirini [29] recommended manual palpation as the most specific and sensitive test (in comparison to EMG and pain pressure threshold) to diagnose headaches types. Bryans [62] recommended the use of the International Classification of Headache disorders 2 (International Headache society-IHS) to categorize headache diagnosis. Beithon [20] suggested a detailed history and examination focused on both physical and neurological examination for differentiation. Diagnosis and differentiation of groups was made mostly by history taking and symptom identification [20, 29, 41].

\section{Intervention}

Two guidelines outlined intervention for cervicogenic headache [45, 62]. Bryans [62] recommends spinal manipulation for cervicogenic headache. Joint mobilization and deep neck flexor exercises were also recommended without the use of them in combination. (Additional file 8: Appendix H). In contrast, Blanpied [45] does not recommend spinal manipulation for acute and chronic NP with headache but only for subacute NP with headache. Active mobility exercise and SNAG exercises were also recommended for acute and subacute categories.

\section{Imaging}

Two CPG's outlined imaging guidelines for headaches [29, 30] (Additional file 9: Appendix I). Both guidelines agreed that for adults with non-acute headache with no change in symptoms or neurological symptoms, routine imaging was not warranted. Other tests outlined in both guidelines with poor diagnostic value included MRI, CT, EMG, Electroencephalography (EEG), Single-photon emission computed tomography (SPECT scan) and Trans cranial Doppler.

\section{Cervical arterial dysfunction (cad)}

Five guidelines were included that pertained to Cervical Arterial Dysfunction (CAD) [31, 32, 34, 35, 70] (Table 4). Publication dates spanned 10 years (20042014). Physiotherapist and chiropractor groups that focused upon diagnosis and pre-manipulative testing protocols authored four of the five guidelines [31, 32, $34,35]$. The remaining guideline focused upon diagnostic imaging and intervention which was authored by a physician group [70]. Four out of the five guidelines did not demonstrate editorial independence [31, $32,34,35]$. All guidelines failed to identify barriers and facilitators to implementation, strategies to improve uptake and outline resource implication of its application. One high AGREE II scoring guideline was identified within this group [70].

\section{Diagnosis}

Four out of five of the guidelines main objectives were for early diagnosis and presentation of Cervical Arterial Dysfunction [31, 32, 34, 35]. Symptoms presented were gathered with risk factors/prognostic factors prior to cervical manipulation or intervention. Much of the diagnosis procedures were focused on the history of the presentation and the identification of symptoms. Rivett [32] reported that dizziness was the most common symptom reported in CAD. A list of different symptoms reported in the guidelines and are detailed in Additional file 11: Appendix K. Furthermore, three guidelines indicated that pre-manipulative testing/end range rotation/quadrant testing was beneficial in determining CAD symptoms [31, 32, 35]. Cervical instability tests as well as palpation lacked evidence to be supported by any guideline but was recommended in the most recent publication [35].

\section{Risk factors}

None of the guidelines detailed prognostic factor associated with poor prognosis. Rather, risk factors were outlined for Cervical Arterial Dysfunction. Rushton [35] indicates that hypertension and cervical instability are two of the largest risk factors to VAI. Anderson and Peacock state absolute risk factors for manipulation are 1) Signs of neurovascular impairment 2) Sharp neck or occipital pain; 3) Severe and persistent headache that is 
unlike another. Three guidelines indicated pain/headache (unlike any other they have ever experience) was a strong risk factor for establishing $\mathrm{CAD}[32,34,35]$. A list of absolute risk factors for manipulation from all the guidelines can be found here (Additional file 12: Appendix L).

\section{Intervention}

Harrigan [70] was the only guideline that presented recommendations regarding interventions for Cervical Arterial Dysfunction. It was recommended that no conclusive evidence supports treatment for CAD, but most clinicians support the use of either anti-coagulation or anti-platelet therapy. Due to the inherent risk of haemorrhagic complications from anti-coagulation therapy, it is not considered in multiple trauma patients. Anti-platelet therapy (aspirin) was presented as a safe and comparable option. This guideline was also the highest scoring within the group and had a high overall score.

\section{Diagnostic imaging}

Harrigan [70] recommended imaging techniques for Cervical Arterial Dysfunction (Additional file 9: Appendix I). Catheter Angiography was listed as the gold standard for diagnosis. Alternatively, magnetic resonance angiography (MRA) or computerized tomography angiography (CTA) were presented as quicker and non-invasive options for diagnosis. Duplex sonography was a less common procedure but also effective.

\section{Discussion}

This review of 46 CPG's found substantial limitations in AGREE II scores pertaining to mechanical NP. In addition, significant heterogeneity was presented in regard to their recommendations. Previous reviews for NP guidelines have concluded that guidelines were overall poor quality and lacked methodological consistency [7, 8]. Our results have agreed with these findings albeit they are improving in more recent years for some NP sub-types. In particular, most guidelines were found to have major limitations with systematic search methods used for evidence, criteria of selecting evidence and adequate descriptions of the strengths and limitations of the body of evidence. The methods for formulating the recommendations were not often described along with a (lack of) link given to the supporting evidence. Also, few guidelines demonstrated editorial independence from their funding bodies or providing an adequate explanation of their applicability. Scores for newer guidelines were significantly greater than older ones. Recent publications (more predominant after 2012) seem to author their publications using the AGREE as a template where older guidelines did not. The acceptance of the AGREE II as a widely used tool to appraise guidelines could be the reasoning for this in recent years.

\section{Inconsistent definitions of NP acuity and severity}

It was surprising to note the significant heterogeneity that was found for the definitions of NP, whiplash and headache in terms of both durations (acuity) and severity of classification. Due to the lack of appropriate classification standards regarding neck pain the interpretation of their findings as a group must be taken with caution. Although many standardized definitions do exist for diagnosis (ICD-10 codes, etc.) many guidelines have not interpreted and collected evidence based upon these differing definitions. This could also be a reason for the large amount of heterogeneity found in the recommendations for diagnosis, prognostic factors, interventions and imaging. In addition, guidelines failed to identify subgroups likely to benefit from interventions. Newer guidelines were better than older ones however no standardized subgrouping method was presented. Finally, few guidelines mentioned dosing of interventions. Dosing is key component to understanding the effectiveness of interventions and should be included for future research of neck pain trials [71].

\section{Interventional recommendation}

Overall, many of the recommendations for interventions have not changed over time for each of the difference NP disorders considered. Active exercise, manipulation and mobilization are recommended by almost every guideline as the main treatment for NP. Throughout the years the number of trials related to NP have increased and the evidence base has grown substantially. However, no overall changes in recommendations have been observed. The interventional guidelines have also followed this trend. If anything, some recommendations have been weakened with the emergence of evidence showing lacking efficacy among treatment modalities, such as was the case with implantable intrathecal infusion systems.

When grading the evidence throughout the publications, many had few "grade A" recommendations and used low quality evidence and consensus to determine their recommendations. Although the amount of evidence may have increased it appears the quality of these that the guidelines are based upon has not.

\section{Strengths and limitations of the review findings}

While many guidelines intertwine recommendations for NP with other areas of pain (such as the lower back), it may be difficult and time-consuming for clinicians to extract the relevant information that could be implemented in their own practice. This review resolves this by filtering the pertinent information from each guideline and summarizing key similarities and differences in simple charts. Furthermore, a clinician who independently reads one of the guidelines included in this systematic review would not have a 
basis of comparison with regards to methodology and compilation of evidence, facing the risk of blindly accepting recommendations without having assessment of quality. This review provided a detailed assessment and comparison for clinicians that are based upon explicit and transparent observations between all available literatures. The use of the widely recognized AGREE II instrument not only provides an objective way of evaluating the quality of guidelines, but also standardizes the assigned scores. Ideally, anyone can view each domain's criteria and know precisely why the guideline in question received the score that it did. Also, guidelines were reviewed by at least two and up to four investigators, reducing potential deviations due to personal subjectivity. Most guidelines were scored very similarly between investigators, suggesting high inter-rater reliability.

It is evident that the classification of NP varied greatly by guideline (Additional file 5: Appendix E), with some guidelines failing to produce any distinction between chronic and acute forms of NP. Other differences in recommendations include ambiguity in recommended dosing and local variations in treatment techniques. All these differences render it challenging to formulate a summary of NP recommendations that will be applicable for all categories of patients. Similarly, many guidelines graded their evidence differently assigning unique meaning to phrases such as "level II evidence or grade A". As such, in order to compare and contrast the guidelines these needed to be ignored and the recommendations were valued as either favoring $(+)$, not favoring $(-)$ or insufficient (I).

Despite great efforts to find and include all relevant NP guidelines, there is a possibility that some guidelines may have been missed by the literature search. Although our search was comprehensive there is always a possibility of some guidelines that were not identified, and this limitation is a feature of all systematic reviews. We did only include CPG's published in English and therefore there may have been some relevant CPGs excluded.

\section{Recommendations for future guideline development}

It is recommended that a standardized classification system be employed when defining NP, and that guidelines create recommendations tailored to certain subgroups. For example, guidelines should clearly distinguish between recommendations for a younger individual with acute NP that is minimal or an elder who has had intense pain for over 5 years. Other improvements in clarity can be made with regards to the recommendations themselves. For instance, guidelines often recommend medication like epidural steroid injections or patient education but fail to clarify effective dose intervals or what constitutes the umbrella term 'education'. Uncertainties among clinicians could not only delay patient recovery, but also exacerbate the condition. Some guidelines pertaining to headache did not distinguish between primary and secondary headache. Future guidelines must not only distinguish between these categories but also give recommendations individually based upon these distinctions. Finally, it is recommended that guideline development groups are comprised of diverse stakeholders that include both professionals and patients, to allow for a more representative scope of NP. Then, the conflicting differences between what physiotherapists, physicians, massage therapists, chiropractors and other professionals are minimized. Only three guidelines (of the 46) obtained the views of patients when developing recommendations $[52,54,56]$. This remains a very large limitation for all guidelines and their development processes.

Most clinical guidelines included within this review did not identify or discuss factors that may facilitate or create barriers for their dissemination and adoption nor have authors given recommendations on how to implement them into clinical practice. These guidelines have translated complex evidence into pragmatic recommendations that are simplified to enhance practice patterns or to be so generic in format that the clinician has no clear direction. In our judgement the majority of guideline developers did not seem to explicitly state how their recommendations would be translated into policy or practice even though these were likely discussed and considered during the development process. This may reflect either a lack of knowledge on how to promote adaptation and implementation or that they felt this was beyond the scope of the guideline developmental process. Determinants are factors that obstruct or enable changes in target professional behaviours or the healthcare delivery process [72]. Increasingly, research on guideline development has been focused on identifying guideline determinants such as frameworks [73], taxonomies [74, 75] and checklists [76] in order to improve their utilization within professional practice. However, further research is needed to develop objective mechanisms by which to choose implementation strategies that match the identified barriers [77]. In the future, guideline developers must consider these determinants for uptake and implementation and by doing so serve to partner to overcome potential barriers; otherwise explicit discussion about how the guideline developers consider these factors would allow them to partner and facilitate strategies to overcome these barriers.

Although many clinical trials are conducted yearly pertaining to mechanical NP, the recommended treatments have not changed much in the past decade. This raises doubts about continuous resource allocation to the 
testing of the same treatment modalities, when the outcomes are reinforcing the same doubt that guidelines have on the efficacy of many of these treatments.

\section{Conclusion}

Most guidelines related to mechanical NP are of poor quality as assessed by the AGREE II but those published from 2012 are rated of higher quality in all domains. Despite an increase in the evidence base, treatment recommendations have not changed significantly over time in their recommendations for interventions used to manage NP.

\section{Additional files}

Additional file 1: Appendix A Search terms used within MEDLINE and all search engines for all areas in the overview of reviews across different clinical areas for the management of NP (DOCX $50 \mathrm{~kb}$ )

Additional file 2: Appendix B PRISMA Flow diagram (DOCX $68 \mathrm{~kb}$ ) Additional file 3: Appendix C Demographics table for all guidelines reviewed (DOCX $17 \mathrm{~kb}$ )

Additional file 4: Appendix D Combined table for all AGREE scores for all guidelines reviewed (DOCX $21 \mathrm{~kb}$ )

Additional file 5: Appendix E Combined table for diagnostic recommendations (Outcome measures, Neck pain classification and clinical tests) for general neck pain and whiplash guidelines. (DOCX $17 \mathrm{~kb}$ )

Additional file 6: Appendix F Combined table for prognostics factors for general neck pain and whiplash guidelines (DOCX $20 \mathrm{~kb}$ )

Additional file 7: Appendix G Combined table for psychological prognostic factors for neck pain and whiplash guidelines (DOCX $19 \mathrm{~kb}$ )

Additional file 8: Appendix H Combined table for interventional/ treatment recommendations for general neck pain and whiplash guidelines (DOCX $30 \mathrm{~kb}$ )

Additional file 9: Appendix I Imaging. Combined table for imaging recommendations for all guidelines (DOCX $17 \mathrm{~kb}$ )

Additional file 10: Appendix J Combined table for diagnostic recommendations among interventional focused quidelines (DOCX $14 \mathrm{~kb})$

Additional file 11: Appendix K Combined table for all invasive techniques recommended by interventional and non-interventional focused guidelines (DOCX $20 \mathrm{~kb}$ )

Additional file 12: Appendix L Combined table for VAl risk factors and testing procedures (DOCX $14 \mathrm{~kb})$

\section{Abbreviations}

CPG: Clinical Practice Guideline; CTA: Computerized Tomography Angiography; MRA: Magnetic Resonance Angiography; NP: Neck Pain; SR: Systematic Review; VAl: Vertebral Artery Insufficiency

\section{Acknowledgements}

Dave Walton who made substantial contributions to the conception and design of the paper.

\section{Funding}

ICON CIHR Knowledge Grant: FRN: 102084; ICON CIHR KTA: FRN: 117420. The role of the funding body did not influence the design of the study, collection, analysis, and interpretation of data as well as the writing of the manuscript.

\section{Availability of data and materials}

All data generated or analysed during the current study are included in this article and its supplementary information files.

\section{Authors' contributions}

PP, PS, JM, AG and AE made substantial contributions to conception and design, acquisition of data, analysis and interpretation of data as well as been involved in drafting the manuscript or revising it critically for important intellectual content. All the authors have given final approval of the version to be published. Each author participated sufficiently in the work to take public responsibility for appropriate portions of the content and agreed to be accountable for all aspects of the work in ensuring that questions related to the accuracy or integrity of any part of the work are appropriately investigated and resolved. In accordance with the ICMJE guidelines, all the above listed authors fulfilled the criteria to qualify for full authorship.

Ethics approval and consent to participate

Ethic approval and consent to participate was not required.

\section{Consent for publication}

This manuscript did not include personal data of any kind therefore no consent was required for publication.

\section{Competing interests}

The review authors have had full possession of the overview process from planning to reporting without funders with potential conflict of interest having any possibility to interfere in the process. No conflicts of interest are declared by each of our authors: Pulak Parikh, Joy Macdermid, Dave Walton, Arshia Eshtiaghi. Anita Gross declares she is a part-time employee of Lifemark Health. Lifemark is an interdisciplinary health care service and is Cervical Overview Group's industry partner. She is also second author of one of the CPGs reviewed. She was not involved in the rating process of the reviews. Pasqualin Santaguida was acknowledged as a contributor to one of the CPGs; she contributed to the diagnostic classification review.

\section{Publisher's Note}

Springer Nature remains neutral with regard to jurisdictional claims in published maps and institutional affiliations.

\section{Author details}

'School of Rehabilitation Science, McMaster University, Hamilton, ON L8S 1C7, Canada. ${ }^{2}$ Department of Health Research Methods, Evidence and Impact (HEI), Faculty of Health Sciences, McMaster University, Hamilton, ON, Canada. ${ }^{3}$ Hand and Upper Limb Centre, St. Joseph Hospital, London, ON, Canada. ${ }^{4}$ Clinical Epidemiology \& Biostatistics, McMaster University, Hamilton, ON, Canada. ${ }^{5}$ Department of Health Science, McMaster University, Hamilton, ON, Canada.

Received: 15 April 2018 Accepted: 30 January 2019

Published online: 14 February 2019

\section{References}

1. Ferrari R, Russell AS. Neck pain. 2003;17(1):57-70. https://doi.org/10.1053/ yberh.2003.269.

2. Hoy $D$, March $L$, Woolf $A$, et al. The global burden of neck pain : estimates from the Global Burden of Disease 2010 study. Ann Rheum Dis. 2014;73: 1309-15. https://doi.org/10.1136/annrheumdis-2013-204431.

3. Co P, Van Der VG, Cassidy JD, et al. The Burden and Determinants of Neck Pain in Workers Results of the Bone and Joint Decade 2000-2010 Task Force on Neck Pain and Its Associated Disorders. J Manipulative Physiol Ther. 2010:33(4):60-74.

4. Elbinoune I, Amine B, Shyen S, Gueddari S, Abouqal R, Hajjaj-Hassouni N. Chronic neck pain and anxiety-depression: prevalence and associated risk factors. Pan Afr Med J. 2016;24:1-8. https://doi.org/10.11604/pamj.2016.24. 89.8831.

5. Haldeman S, Carroll L, Cassidy JD, et al. The bone and joint decade 20002010 task force on neck pain and its associated disorders: executive summary. Spine (Phila Pa 1976). 2008;33(4 Suppl):S5-7. https://doi.org/10. 1097/BRS.0b013e3181643f40. 
6. Graham R, Mancher M, Wolmann DM, Greenfield S, Steinberg E. Clinical Practice Guidelines We Can Trust; 2011. http://www.nap.edu/openbook. php?record_id=13058.

7. Wong JJ, Côté $\mathrm{P}$, Shearer HM, et al. Clinical practice guidelines for the management of conditions related to traffic collisions: a systematic review by the OPTIMa collaboration. Disabil Rehabil. 2014;8288(416):1-19. https:// doi.org/10.3109/09638288.2014.932448.

8. Wong JJ, Cotet P, Sutton DA, et al. Clinical practice guidelines for the noninvasive management of low back pain: A systematic review by the Ontario Protocol for Traffic Injury Management (OPTIMa) Collaboration. Eur J Pain (United Kingdom). 2016;21:201-16. https://doi.org/10.1002/ejp.931.

9. Saturno PJ, Medina F, Valera F, Montilla J, Escolar P, Gascón JJ. Validity and reliability of guidelines for neck pain treatment in primary health care. $A$ nationwide empirical analysis in Spain. Int J Qual Heal care J Int Soc Qual Heal Care. 2003;15(6):487-93.

10. Miller J, Gross A, D'Sylva J, et al. Manual therapy and exercise for neck pain: a systematic review. Man Ther. 2010;15(4):334-54. https://doi.org/10.1016/j. math.2010.02.007.

11. Gross A, Miller J, D'Sylva J, et al. Manipulation or mobilisation for neck pain: a Cochrane review. Man Ther. 2010;15(4):315-33. https://doi.org/10.1016/j. math.2010.04.002

12. Horn ME, Brennan GP, George SZ, Harman JS, Bishop MD. Clinical Outcomes , Utilization, and Charges in Persons With Neck Pain Receiving Guideline Adherent Physical Therapy. Eval Health Prof. 2016;39(4):421-34. https://doi. org/10.1177/0163278715583510.

13. Suman A, Dikkers MF, Schaafsma FG, van Tulder MW, Anema JR. Effectiveness of multifaceted implementation strategies for the implementation of back and neck pain guidelines in health care: a systematic review. Implement Sci. 2016;11(1):126. https://doi.org/10.1186/ s13012-016-0482-7.

14. Santaguida PL, Keshavarz H, Carlesso LC, et al. A description of the methodology used in an overview of reviews to evaluate evidence on the treatment, harms, diagnosis/classification, prognosis and outcomes used in the management of neck pain. Open Orthop J. 2013;7:461-72. https://doi. org/10.2174/1874325001307010461.

15. Hoffmann-eßer W, Siering U, Neugebauer EAM, Brockhaus C, Lampert U, Eikermann M. Guideline appraisal with AGREE II : Systematic review of the current evidence on how users handle the 2 overall assessments. PLoS One. 2017;3:1-15

16. Scottish Intercollegiate Guidelines Network (SIGN). Management of chronic pain. Edinburgh: SIGN; 2013. (SIGN publication no. 136). [December 2013]. Available from URL: http://www.sign.ac.uk.

17. Bussieres AE, Stewart G, Al-Zoubi F, et al. The Treatment of Neck Pain???Associated Disorders and Whiplash-Associated Disorders: A Clinical Practice Guideline. J Manipulative Physiol Ther. 2016;39(8):523-564.e27. https://doi.org/10.1016/j.jmpt.2016.08.007.

18. Moore A, Jackson A, Jordan J, et al. Clinical Practice Guidelines for the physiotherapy management of whiplash associated disorder. Chart Soc Physiother London, Engl. 2010;4(93):1999.

19. Manchikanti L, Singh V, Helm S, Schultz DM, Datta S, Hirsch JA. An introduction to an evidence-based approach to interventional techniques in the management of chronic spinal pain. Pain Physician. 2009;12:E1-E33 http://www.ncbi.nlm.nih.gov/pubmed/19668280.

20. Beithon J, Gallenberg M, Johnson K, Kildahl P, Krenik J, Liebow M, Linbo L, Myers C, Peterson S, Schmidt J, Swanson J. Institute for Clinical Systems Improvement. Diagnosis and Treatment of Headache. http://bit.ly/ Headache0113. Updated January 2013.

21. French S, Walker B, Cameron M, Pollard HL, Vitiello A, Reggars J, Werth P, Comrie D. Risk management for chiropractors and osteopaths: imaging guidlines for conditions commonly seen in practice. Rev Exp. 2003;11(2):41-8.

22. Bregeon F, Francoise B. Agenee Natl D'Accreditation et d'Evaluation en Sante Physiotherapy in common neck pain and whiplash: ANAES guidelines. 2003:1-10. https://www.hassante.fr/portail/upload/docs/application/pdf/ physioth_common_neck_pain_guidelines.pd.

23. TRACsa. Clinical guidelines for best practice management of acute and chronic whiplash-associated disorders. Cent Trauma Inj Recover. 2008:86 http://espace. library.uq.edu.au/view/UQ:266894.

24. Mercer C, Jackson A, Moore A. Developing clinical guidelines for the physiotherapy management of whiplash associated disorder (WAD). Int J Osteopath Med. 2007;10(2-3):50-4. https://doi.org/10.1016/j.ijosm.2007.02. 003.
25. International Chiropractors Association of California. Management of whiplash associated disorders. Sacramento (CA): International Chiropractors Association of California; 2009. https://www.beckleychiropractor.com/ uploads/2/6/9/3/26938122/national_whiplash_guidelines.pdf.

26. Bryans $R$, Anderson-Peacock E, Descarreaux M, et al. Practice Guide for the Management of Whiplash Disorders in Adults. 2010.

27. Motor Accidents Authority. Guidelines for the Management of Acute Whiplash-Associated Disorders - for Health Professionals; 2014.

28. Easa J, Kreiner DS, Ghogawala Z, Mazanec D, Shaffer W, Summers J. Cervical Epidural Steroid InjectionsReview \& Recommendation Statement. North Am Spine Soc. 2011:1-37 https://www.spine.org/Documents/ResearchClinicalCare/ CESIReviewRecStatement.pdf.

29. Sandrini G, Friberg L, Coppola G, et al. Neurophysiological tests and neuroimaging procedures in non-acute headache (2nd edition). Eur J Neurol. 2011;18(3):373-81. https://doi.org/10.1111/j.1468-1331.2010.03212.x.

30. Douglas AC, Wippold FJ, Broderick DF, et al. ACR appropriateness criteria headache. J Am Coll Radiol. 2014;11(7):657-67. https://doi.org/10.1016/j.jacr. 2014.03.024

31. Magarey ME, Rebbeck T, Coughlan B, Grimmer K, Rivett DA, Refshauge K. Pre-manipulative testing of the cervical spine review, revision and new clinical guidelines. Man Ther. 2004;9(2):95-108. https://doi.org/10.1016/j. math.2003.12.002.

32. Rivett D, Shirley D, Magarey M, Refshauge KM. Aust Physiother Assoc. Clinical Guidelines for Assessing Vertebrobasilar Insufficiency in the Management of Cervical Spine Disorders. 2006:1-14. https://australian. physio/tools/clinical-practice/cervical-spine.

33. Anderson-Peacock E, Blouin JS, Bryans R, et al. Chiropractic clinical practice guideline: evidence-based treatment of adult neck pain not due to whiplash. J Can Chiropr Assoc. 2005;49(3):158-209.

34. Anderson-Peacock E, Bryans R, Danis N, et al. A clinical practice guideline update for the treatment of adult neck pain without whiplash. J Can Chiropr Assoc. 2007;51(1):19-22 http://www. pubmedcentral.nih.gov/articlerender.fcgi?artid=1924659\&tool= pmcentrez\&rendertype=abstract.

35. Rushton A, Rivett D, Carlesso L, Flynn T, Hing W, Kerry R. International framework for examination of the cervical region for potential of cervical arterial dysfunction prior to Orthopaedic manual therapy intervention. Man Ther. 2014;19(3):222-8. https://doi.org/10.1016/j.math. 2013.11.005.

36. Physician Advisory Committee. Oklahoma Guidelines for the Treatment of the Cervical Spine.; 2009.

37. State of New York Department of Insurance to the Workers Compensation. Cervical Injury Medical Treatment Guidelines.; 2008.

38. Brosseau L, Wells GA, Tugwell P, et al. Ottawa panel evidence-based clinical practice guidelines on therapeutic massage for neck pain. J Bodyw Mov Ther. 2012;16(3):300-25. https://doi.org/10.1016/j.jbmt.2012.04.001.

39. Bonaiuti D, Brugnoni G, Ceravolo G, Cerri C, Toffola ED, Fiore P. The Italian Society of Physical and Rehabilitation Medicine ( SIMFER ) recommendations for neck pain. G Ital Med Lav Ergon. 2013;33:36-50.

40. Newman JS, Weissman BN, Angevine PD, Appel M, Arnold E, Bencardino JT. Evidence table. Reston: American College of Radiology; 2013. p. 24. https:// www.guidelinecentral.com/summaries/acr-appropriateness-criteria-chronicneck-pain/\#section-society.

41. Bryans R, Decina P, Descarreaux M, et al. Evidence-based guidelines for the chiropractic treatment of adults with neck pain. J Manip Physiol Ther. 2014; 37(1):42-63. https://doi.org/10.1016/j.jmpt.2013.08.010.

42. State of Colorado Department of Labor. Cervical Spine Injury Medical Treatment Guidelines. 2014.

43. Bussieres AE, Taylor JAM, Peterson C. Diagnostic imaging practice guidelines for musculoskeletal complaints in adults-an evidence-based approach-part 3 : spinal disorders. J Manip Physiol Ther. 2008;31(1):33-88. https://doi.org/10. 1016/j.jmpt.2007.11.003.

44. Bono CM, Ghiselli G, Gilbert TJ, et al. An evidence-based clinical guideline for the diagnosis and treatment of cervical radiculopathy from degenerative disorders. Spine J. 2011;11(1):64-72. https://doi.org/ 10.1016/j.spinee.2010.10.023.

45. Blanpied PR, Gross AR, Elliott JM, et al. Neck Pain : Revision 2017 Clinical Practice Guidelines Linked to the International Classification of Functioning , Disability and Health From the Orthopaedic Section of the American Physical Therapy Association. J Orthop Sport Phys Ther. 2017;47(7):A1-A52. https://doi.org/10.2519/jospt.2017.0302. 
46. Leigh T, Yardley T, Smith C, et al. Clinical Practice Guidelines for Physiotherapy Management of Patients with Whiplash Associated Disorders (WAD). 2005;(604):23. https://bcphysio.org/sites/default/files/file_attachments/ resource/wad guidelines.pdf.

47. Boswell MV, Manchikanti L, Staats PS, et al. Evidence-based practice guidelines for interventional techniques in the management of chronic spinal pain. Pain Physician. 2005;6(1):3-81.

48. Boswell MV, Trescot AM, Datta S, et al. Interventional techniques: evidencebased practice guidelines in the management of chronic spinal pain. Pain Physician. 2007:10(1):7-111.

49. Manchikanti L, Boswell MV, Singh V, et al. Comprehensive review of neurophysiologic basis and diagnostic interventions in managing chronic spinal pain. Pain Physician. 2009;12:E71-E120.

50. Manchikanti L, Helm S, Singh V, et al. An algorithmic approach for clinical management of chronic spinal pain. Pain Physician. 2009;12(4):E225-64. https://doi.org/10.4103/0028-3886.190252.

51. Kjaer P, Kongsted A, Hartvigsen J, et al. National clinical guidelines for nonsurgical treatment of patients with recent onset neck pain or cervical radiculopathy. Eur Spine J. 2017;26(9):2242-57. https://doi.org/10.1007/ s00586-017-5121-8.

52. Guzman J, Haldeman S, Carroll LJ, et al. Clinical practice implications of the bone and joint decade 2000-2010 task force on neck pain and its associated disorders. From concepts and findings to recommendations. J Manip Physiol Ther. 2009;32(2 SUPPL):S227-43. https://doi.org/10.1016/j. jmpt.2008.11.023.

53. Group AAMPG. Evidence-based management of acute musculoskeletal pain. Aust Acad Press. 2010;370(9599):1595-6. http://ccpor.ca/wp-content/ uploads/Evidenced-Based-Management-of-Acute-Musculoskeletal-Pain-2004. pdf.

54. Cote P, Wong JJ, Sutton D, et al. Management of neck pain and associated disorders: a clinical practice guideline from the Ontario protocol for traffic injury management (OPTIMa) collaboration. Eur Spine J. 2016;25(7):2000-22. https://doi.org/10.1007/s00586-016-4467-7.

55. Compensation PA. OKLAHOMA Guidelines for treatment of developed and adopted of the Evaluation; 2009.

56. Bier JD, Scholten-peeters WGM, Staal JB, et al. Clinical practice guideline for physical therapy assessment and treatment in patients with nonspecific neck pain. Phys Ther. 2018;98(3):162-71.

57. Childs JD, Cleland JA, Elliott JM, et al. Neck pain. J Orthop Sport Phys Ther. 2008:38(9):A1-A34. https://doi.org/10.2519/jospt.2008.0303.

58. Brown GK, Nicassio PM. Development of a questionnaire for the assessment of active and passive coping strategies in chronic pain patients. PAIN ${ }^{\circledR}$. 1987; 31(1):53-64 doi:https://doi.org/10.1016/0304-3959(87)90006-6.

59. ANAES. P hysiotherapy in common neck pain and whiplash M ay 2003 Guidelines Department. 2003.

60. French S, Walker B, Cameron M, Pollard HL, Vitiello A, Reggars J, Werth P, Comrie D. Reviews \& Experimental Risk Management for Chiropractors and Osteopaths: Imaging Guidelines for Conditions Commonly Seen in practice. Rev Exp. 2003;11(2):41-8.

61. Bekkering G, Hendriks H, Lanser K, Rab VO, Ggm IXS. Clinical practice guidelines for physical therapy in patients with whiplash-associated disorders. Epidemiology. 2003:1-30. https://www.researchgate.net/profile/ Erik_Hendriks2/publication/224983858_Clinical_practice_guidelines_for physical_therapy_in_patients_with_whiplash-associated_disorders/links/ 09e41504e16f8330a2000000.pdf.

62. Bryans R, Descarreaux M, Duranleau M, et al. Evidence-based guidelines for the chiropractic treatment of adults with headache. J Manip Physiol Ther. 2011;34(5):274-89. https://doi.org/10.1016/j.jmpt.2011.04.008.

63. Motor Accidents Authority. Guidelines for the Management of Acute WhiplashAssociated Disorders for Health Professionals, Third Edition 2014:; 2014.

64. A M, A J, J J, et al. Whiplash Associated Disorder (WAD ), vol. 4; 2010.

65. Spitzer W, Skovron M, Rachid SL, Cassidy J, Duranceau J, Suissa S, Zeiss E. Scientific Monograph of the Quebec Task Force on Whiplash-Associated Disorders: Redefining "Whiplash" and it's Management. Spine (Phila Pa 1976). 1995;20:1-73.

66. Manchikanti L, Boswell MV, Singh V, et al. Comprehensive Evidence-Based Guidelines for Interventional Techniques in the Management of Chronic Spinal Pain; 2009. p. 699-802

67. Manchikanti L, Singh V, Derby R, et al. Review of occupational medicine practice guidelines for interventional pain management and potential implications. Pain Physician. 2008;11(3):271-89.
68. Manchikanti L. Evidence-based medicine, Systematic Reviews, and Guidelines in Interventional Pain Management, Part I: Introduction and General Considerations; 2008. p. 161-86.

69. Manchikanti L, Abdi S, Atluri S, et al. An update of comprehensive evidencebased guidelines for interventional techniques in chronic spinal pain. Part II: guidance and recommendations. Pain Physician. 2013;16(2 Suppl):S49-283.

70. Harrigan MR, Hadley MN, Dhall SS, et al. Management of vertebral artery injuries following non-penetrating cervical trauma. Neurosurgery. 2013; 72(SUPPL.2):234-43. https://doi.org/10.1227/NEU.0b013e31827765f5.

71. Goldsmith $\mathrm{CH}$, Gross AR, MacDermid J, Santaguida PL, Miller J. What does the evidence tell us about Design of Future Treatment Trials for whiplashassociated disorders? Spine (Phila Pa 1976). 2011;36(25):S292-302. https:// doi.org/10.1097/BRS.0b013e3182388259.

72. Krause J, Van Lieshout J, Klomp R, et al. Identifying determinants of care for tailoring implementation in chronic diseases: an evaluation of different methods. Implement Sci. 2014;9(1):1-12. https://doi.org/10.1186/s13012-014-0102-3.

73. Alonso-Coello P, Oxman A, Moberg J, Brignardello-Petersen R, Akl E, Davoli M, Treweek S, Mustafa R, Vandvik P, Meerpohl J, Guyatt G, Schunemann H TGWG. GRADE: Evidence to Decision (EtD) frameworks - a systematic and transparent approach to making well informed healthcare choices. 2: Clinical Practice Guidelines. BMJ. 2016;353(i2089):1-9. https://doi.org/10. 1016/j.zefa.2018.05.004.

74. Willson ML, Vernooij RWM, Gagliardi AR, et al. Questionnaires used to assess barriers of clinical guideline use among physicians are not comprehensive, reliable, or valid: a scoping review. J Clin Epidemiol. 2017:86:25-38, https://doi.org/10.1016/j.jclinepi.2016.12.012.

75. Schünemann HJ, Wiercioch W, Brozek J, et al. GRADE evidence to decision (EtD) frameworks for adoption, adaptation, and de novo development of trustworthy recommendations: GRADE-ADOLOPMENT. J Clin Epidemiol. 2017:81:101-10. https://doi.org/10.1016/j.jclinepi.2016.09.009.

76. Flottorp SA, Oxman AD, Krause J, et al. A checklist for identifying determinants of practice: A systematic review and synthesis of frameworks and taxonomies of factors that prevent or enable improvements in healthcare professional practice. Implement Sci. 2013;8(1). https://doi.org/10. 1186/1748-5908-8-35.

77. Gagliardi AR, Alhabib S. Trends in guideline implementation: a scoping systematic review. Implement Sci. 2015;10:54. https://doi.org/10.1186/ s13012-015-0247-8.

\section{Ready to submit your research? Choose BMC and benefit from:}

- fast, convenient online submission

- thorough peer review by experienced researchers in your field

- rapid publication on acceptance

- support for research data, including large and complex data types

- gold Open Access which fosters wider collaboration and increased citations

- maximum visibility for your research: over $100 \mathrm{M}$ website views per year

At BMC, research is always in progress.

Learn more biomedcentral.com/submissions 